\title{
Galbraith, Robert. O Chamado do Cuco. Tradução de Ryta Vinagre. Rio de Janeiro: Rocco, 2013. 448 p.
}

\author{
Winston Carlos Martins Junior 1 \\ ${ }^{1}$ Universidade Federal Fluminense, Rio de Janeiro, Rio de Janeiro, Brasil
}

\section{Introdução}

A presente resenha busca avaliar a tradução de marcas de oralidade no romance The Cuckoo's Calling (2013), de Robert Galbraith (pseudônimo de J. K. Rowling), traduzido para o Brasil por Ryta Vinagre sob o título O Chamado do Cuco (2013).

Trata-se de um romance policial inglês da autoria de J. K. Rowling, publicado em 2013 sob o pseudônimo Robert Galbraith. O livro se passa em Londres no início da década de 2010 e conta a história de Cormoran Strike, um ex-militar que perdeu parte de uma perna na guerra do Afeganistão e, em decorrência disso, passa a trabalhar como detetive particular. O enredo se inicia quando Strike é contratado pelo nobre inglês John Bristow para investigar as circunstâncias do suposto suicídio de sua irmã, a supermodelo Lula Landry. Logo no início da obra, Strike conhece Robin Ellacott, a nova secretária temporária de seu escritório, que rapidamente demonstra seu interesse pelo mundo da investigação, tornando-se uma grande aliada e parceira, e auxiliando valiosamente nas perquirições.

Para realizar a presente resenha, buscar-se-á analisar, primeiramente, aspectos teóricos da temática da representação da lingua- 
gem oral na literatura, bem como seu contraste com a chamada norma-padrão, e a norma culta. Será também necessário compreender como autores do campo da tradução compreendem tais marcas de oralidade em textos literários, e quais consequências a presença delas pode trazer para a tradução de uma obra. Em seguida, serão analisadas as referidas marcas na obra de Galbraith, com o intuito de compreender em quais momentos e com que frequência elas aparecem para, por fim, serem comparadas as marcas orais no original com as da tradução.

\section{Norma-padrão/norma culta, variação oral e sua representa- ção literária}

Um conceito essencial para a presente análise é o de norma-padrão, e sua relação com a chamada norma culta, já que a própria concepção de variação oral surge em contraste a esses dois conceitos.

A esse respeito, Bagno (127) considera ser imprescindível distinguir entre norma-padrão, norma culta e as variedades linguísticas reais efetivamente faladas pelos indivíduos em geral. A primeira, segundo o autor, seria aquela língua vista como "certa", consistindo no conjunto de regras determinadas pelos gramáticos normativos. Por outro lado, a norma culta tratar-se-ia da fala de fato realizada por falantes letrados, em geral moradores de zonas urbanas. Por fim, as variedades linguísticas reais seriam as diferentes formas de fala das pessoas em geral.

Um ponto muito importante enfatizado por Bagno (127-8) é o fato de que a norma-padrão não é uma variedade linguística; ela nada mais é do que uma abstração, não sendo uma variedade falada observável empiricamente. Em verdade, o que existe são a norma culta ("o conjunto de variedades urbanas de prestígio realmente empregadas pelas camadas privilegiadas da população" - (Bagno 128)) e as inúmeras variedades orais. 
A respeito do tema, Alexandra Assis Rosa (209) assevera que o discurso oral e escrito, os dialetos e mesmo os sotaques variam e dependem de informação contextual. Assim, cada grupo possuirá sua própria variedade, a qual é marcada por sua própria história e cultura.

Em seu trabalho (que se situa no campo da tradução, muito embora trate de assuntos bastante caros à sociolinguística), a autora considera as variedades linguísticas como

(1) um padrão de sons, estruturas gramaticais, vocabulário, textura, estrutura (forma linguística) que podem conter (2) informação contextual sobre usos e usuários, em termos de tempo, espaço, grupo sociocultural, situação e individualidade (significado comunicativo), que também é associado com (3) um dado status e prestígio sociais dentro de uma comunidade linguística. ${ }^{1,2}$

Diante disso, a questão do prestígio é essencial no que diz respeito às diferentes variedades orais. Baseando-se em Labov, Rosa (210) demonstra que a competência comunicativa de cada indivíduo traz uma importante compreensão de um conjunto de características linguísticas com significado comunicativo e valor sociocultural. Em outras palavras, por meio da fala de uma pessoa é possível identificar sua idade, a época e o espaço social em que fala, o grupo a que pertence, dentre outras características. Atrelada a isso está uma série de avaliações e julgamentos que os indivíduos fazem uns dos outros e que confere a alguns maior prestígio do que a outros.

${ }^{1}$ [...] (1) a patterning of sounds, grammatical structures, vocabulary, texture, structure (linguistic form) that may carry (2) contextual information on users and uses, in terms of time, space, sociocultural group, situation and individuality (communicative meaning), that is also associated with (3) a given social status and prestige within a linguistic community." Tradução nossa.

${ }^{2}$ Rosa, ibidem. 210. 
Ademais, é também necessário enfatizar que inúmeros são os motivos que podem levar um escritor a se utilizar de um dialeto literário. Apesar disso, é inegável que, de forma semelhante às distintas variedades faladas pelos indivíduos, as marcas de oralidade em textos literários sofrem juízos de valor por parte dos leitores (Rosa 212).

Acerca disso, Paulo Henriques Britto (apud Amorim 139-40) enfatiza que algumas delas (em geral aquelas realizadas na norma culta ou que muito se aproximam dela) são consideradas não estigmatizadas. Tratar-se-ia quase de "erros aceitáveis" de gramática, já que até mesmo pessoas altamente escolarizadas os cometeriam. Outras marcas, por outro lado, são vistas como estigmatizadas; são os desvios da norma-padrão que os indivíduos em geral (principalmente aqueles escolarizados) não realizam, mas sim pessoas com baixa escolaridade, ou pertencentes a grupos socialmente marginalizados.

Consequentemente, o que se percebe ao se analisar muitas obras literárias de prestígio em língua portuguesa é a predominância da norma culta na fala do narrador e mesmo na de vários personagens. Não apenas isso: é até mesmo possível observar a presença de um elevado registro na fala de vários personagens em narrativas - característica essa que, muitas vezes, não soa natural a um falante comum. Em geral, quanto mais escolarizado um personagem num romance, mais padronizada será sua fala, sendo as marcas de oralidade por ele realizadas (se é que existem) comumente restritas àquelas não estigmatizadas.

Assim, não é à toa que Britto ${ }^{3}$ afirma que a distância entre o que se fala e o que se escreve em língua portuguesa é bastante perceptível, sendo maior do que a distância em outras línguas, como é o caso do inglês.

Nesse contexto, Rosa (214) enfatiza que, ao se deparar com marcas de oralidade num texto, o tradutor deverá escolher como traduzi

${ }^{3}$ Ibidem 83 apud Amorim 141.

Cad. Trad., Florianópolis, v. 40, n⿳ 3, p. 250-263, set-dez, 2020. 
-las. A partir disso, a autora menciona as três principais estratégias de tradução de variedades orais literárias: normalização, centralização e descentralização. A primeira ocorre quando o discurso de menos prestígio no texto de partida é traduzido como padrão no texto de chegada; já a centralização diz respeito às situações em que o discurso menos prestigiado do texto de partida é traduzido de modo mais prestigiado, embora ainda não totalmente normalizado, no texto de chegada; por fim, a descentralização acontece em casos em que o texto de partida padrão é traduzido como um discurso de menos prestígio.

Diante do que se expôs, e com base nos elementos teóricos aqui elencados, observar-se-á no seguinte tópico o uso de marcas de oralidade na obra The Cuckoo's Calling (2013), de Robert Galbraith, bem como em sua tradução brasileira, O Chamado do Cuco (2013), realizada por Ryta Vinagre.

\section{Marcas de oralidade em The Cuckoo's Calling e sua tradução - O Chamado do Cuco}

No geral, o livro possui um registro bastante alto. A narração dos eventos da história, bem como a descrição (sempre bastante minuciosa) dos locais em que os eventos ocorrem, são bastante objetivas e utilizam um vocabulário e estruturas bastante rebuscados e distantes da linguagem falada. Isso, todavia, não significa que não haja marcas de oralidade na obra. Muito pelo contrário: é possível perceber variação na fala de inúmeros personagens ao longo do livro, embora em intensidades distintas e com níveis diferentes de estigma.

Ao conduzir a investigação na história, Strike e Robin entram em contato com pessoas dos mais diferentes tipos: policiais, um motorista, uma supermodelo, nobres ingleses, um estilista, vendedores em lojas de grife e muitos outros. Com base nas conversas que eles têm, percebe-se nitidamente que fatores como a origem dos personagens (se de Londres, da periferia da metrópole, ou outras 
cidades inglesas), seu nível de escolaridade, o grupo social ao qual pertencem, bem como seu poder aquisitivo, influenciam diretamente a forma como eles se comunicam, além da intensidade de seus desvios ou da aproximação em relação à norma culta.

Os personagens com os quais o leitor mais tem contato e cujas falas mais frequentemente se lê são, por óbvio, os principais, Strike e Robin. Ambos iniciaram cursos universitários, mas desistiram deles por motivos pessoais (Strike, para se juntar ao exército inglês; Robin, em virtude de um trauma decorrente de um ataque). Ainda assim, os dois personagens possuem um alto nível de erudição (em alguns momentos da obra, por exemplo, Strike até mesmo recita expressões em latim), de modo que suas falas (no original, em inglês) revelam, no geral, poucos desvios da norma culta, a não ser por alguns não estigmatizados, como contrações comuns (I'm para I am; D'you para Do you, etc.). Pode-se ainda mencionar que a fala de Strike possui algumas palavras de baixo calão com certa frequência (embora nenhuma de uso muito estigmatizado), mas, à exceção disso, suas falas seguem quase sempre a norma culta.

Observem-se, a seguir, alguns exemplos de marcas de oralidade nas falas de Strike, bem como as traduções para o português brasileiro (as marcas de oralidade em ambos os idiomas foram marcadas em negrito): ${ }^{4}$

Tabela 1: Exemplos de Marca de Oralidade

\begin{tabular}{|l|l|}
\hline \multicolumn{1}{|c|}{ The Cuckoo's Calling } & \multicolumn{1}{c|}{ O Chamado do Cuco } \\
\hline $\begin{array}{l}\text { STRIKE: “ 'Scuse me a } \\
\text { moment." (Galbraith 16) }\end{array}$ & $\begin{array}{l}\text { - Me dê licença um minutinho. } \\
\text { (Galbraith 24) }\end{array}$ \\
\hline
\end{tabular}

${ }^{4}$ As falas de Robin revelam desvios tão ínfimos da norma culta que se preferiu aqui não as mencionar.

Cad. Trad., Florianópolis, v. 40, n⿳0 3, p. 250-263, set-dez, 2020. 


\begin{tabular}{|l|l|}
\hline $\begin{array}{l}\text { STRIKE: "You fat cunt," he } \\
\text { said aloud. "You knackered old } \\
\text { dinosaur." (Galbraith 49) }\end{array}$ & $\begin{array}{l}\text { - Seu gordo babaca - disse em } \\
\text { voz alta. - Dinossauro velho e } \\
\text { acabado. (Galbraith 57) }\end{array}$ \\
\hline $\begin{array}{l}\text { "Y're a very nice girl," said } \\
\text { Strike. "Y'are. Y're a very nice } \\
\text { p'son. I've noticed," he said, } \\
\text { nodding solemnly. "Yes. 'Ve } \\
\text { noticed that." }\end{array}$ & $\begin{array}{l}\text { - Vochê é uma garota legal - } \\
\text { disse Strike. - É, chim. Você é } \\
\text { uma boa pechoa. Eu notei - disse } \\
\text { ele, assentindo solenemente. - É. } \\
\text { "There'z no need," Strike told } \\
\text { him, "t'shout. No need. Fuckin' } \\
\text { rude." (Galbraith 302) }\end{array}$ \\
$\begin{array}{l}\text { Eu notei icho. } \\
\text { (..) }\end{array}$ \\
- Não prechija - disse-lhe Strike \\
- gritar. Não prechija. Sheu \\
grocho de merda. (Galbraith \\
301-2)
\end{tabular}

Fonte: $\mathrm{O}$ autor

No primeiro trecho, percebe-se que a tradutora buscou representar a oralidade da expressão ('scuse em vez de excuse) por meio do uso do pronome oblíquo no início da frase (algo que contradiz a gramática normativa do português, mas é amplamente realizado no Brasil), além do uso do diminutivo em minutinho. No segundo, por outro lado, percebe-se uma nítida suavização da fala do personagem: substituiu-se a palavra de baixo calão cunt (considerada extremamente grosseira na língua inglesa) pelo termo português babaca, que nem de longe é tão ofensivo quanto a expressão original. Logo, conclui-se que ambos os exemplos são casos de centralização, de acordo com o quadro teórico proposto por Rosa.

Quanto ao terceiro trecho, é importante mencionar que se trata de uma fala de Strike em um momento em que o personagem se encontra bastante embriagado, não conseguindo mais pronunciar as palavras corretamente. Diante disso, a tradutora optou por substituir o som de /s/ pelo de / $/$, e o de /z/ pelo de /3/, algo que se assemelha às falas de bêbados em filmes e programas de televisão. 
Para além de Strike, alguns personagens secundários com alto nível de escolaridade também utilizam marcas de oralidade em suas falas. Pode-se citar os exemplos de Charlotte Campbell, a ex-namorada problemática de Strike, e Eric Wardle, o policial que liderou a investigação sobre a morte de Lula Landry. Em geral, os desvios da norma culta realizados por tais personagens (e, também, por outros secundários com alto nível de escolaridade) se dão por meio do uso de palavras de baixo calão, ainda que, em geral, tais expressões não sejam consideradas excessivamente estigmatizadas. Observem-se os excertos abaixo, de Charlotte e Wardle, respectivamente:

Tabela 2: Excertos de Charlotte e Wardle

\begin{tabular}{|c|c|}
\hline The Cuckoo's Calling & O Chamado do Cuco \\
\hline $\begin{array}{l}\text { CHARLOTTE: “Don't you dare } \\
\text { fucking investigate me. Don't you } \\
\text { dare treat me like some drugged- } \\
\text { up squaddie. I am not a fucking } \\
\text { case to be solved; you're supposed } \\
\text { to love me and you won't take my } \\
\text { word even on this..." (Galbraith 53) }\end{array}$ & $\begin{array}{l}\text { "Não se atreva a me investigar, } \\
\text { porra. Não se atreva a me tratar } \\
\text { como um soldadinho drogado. Não } \\
\text { sou uma merda de um caso a ser } \\
\text { resolvido; você devia me amar } \\
\text { e não aceita minha palavra nem } \\
\text { mesmo nisso..." (Galbraith 61) }\end{array}$ \\
\hline $\begin{array}{l}\text { WARDLE: "Can he explain how } \\
\text { a murderer got into the pool area, } \\
\text { or back to it, without walking } \\
\text { right past him? A fucking pool," } \\
\text { said Wardle, "nearly as big as } \\
\text { the one I've got at my gym, and } \\
\text { all for the use of three fucking } \\
\text { people. A gym on the ground } \\
\text { floor behind the security desk. } \\
\text { Underground fucking parking. } \\
\text { Flats done up with marble and } \\
\text { shit like...like a fucking five-star } \\
\text { hotel." (Galbraith 132) }\end{array}$ & $\begin{array}{l}\text { - Ele pode explicar como um } \\
\text { assassino entrou na área da } \\
\text { piscina, ou saiu por ela, sem } \\
\text { passar por ele? Uma merda } \\
\text { de piscina - disse Wardle - } \\
\text { do tamanho da que tem na } \\
\text { minha academia e só para o } \\
\text { uso daqueles babacas. Uma } \\
\text { academia no térreo ao lado } \\
\text { da portaria. Uma merda } \\
\text { de garagem subterrânea. } \\
\text { Apartamentos feitos de mármore } \\
\text { e trecos assim... parece um hotel } \\
\text { cinco estrelas. (Galbraith 140) }\end{array}$ \\
\hline
\end{tabular}

Fonte: O Autor

Cad. Trad., Florianópolis, v. 40, n⿳ 3, p. 250-263, set-dez, 2020. 
É interessante observar que, em certos casos, a tradutora buscou traduzir alguns dos termos de baixo calão presentes no texto original, a exemplo do palavrão fucking usado por Charlotte, traduzido por porra e merda. Em outros casos, todavia, é possível perceber uma certa suavização da intensidade de alguns xingamentos: three fucking people, na frase de Wardle, torna-se daqueles babacas na tradução; além disso, a expressão shit like acabou tornando-se trecos assim, expressão que nem sequer é considerada de baixo calão na língua portuguesa. Nota-se, assim, uma tentativa de manutenção do registro, embora marcada por traços de centralização.

Ademais, algumas marcas de oralidade mais salientes podem ser observadas na fala de personagens com baixa escolaridade, como Derrick Wilson, imigrante jamaicano e porteiro do prédio de luxo em que morava Lula Landry, Rochelle Onifade, a amiga sem-teto da modelo falecida, ou Marlene Higson, a mãe biológica de Lula, residente da periferia de Londres, que se viu obrigada a entregar a filha para a adoção por não ter condições financeiras de criá-la. Seguem exemplos dos referidos personagens:

Tabela 3: Exemplos personagens com baixa escolaridade

\begin{tabular}{|l|l|}
\hline \multicolumn{1}{|c|}{ The Cuckoo's Calling } & \multicolumn{1}{c|}{ O Chamado do Cuco } \\
\hline WILSON: “Just in and out past & - Só passando pela mesa, \\
the desk. She always said hullo & entrando e saindo. Ela sempre \\
and please and thank you, which & dizia um oi, por favor e \\
is more'n a whole lotta these rich & obrigada, mais do que muitos \\
fuckers manage," said Wilson & desses merdinhas ricos \\
laconically. "Longest chat we ever & conseguem fazer - disse Wilson \\
had was about Jamaica. She was & laconicamente. - A conversa \\
thinking of doing a job over there; & mais comprida que tivemos foi \\
asking me where tuh stay, what's & sobre a Jamaica. Ela pensava \\
it like. And I got her autograph & em fazer um trabalho por lá; me \\
for mi nephew, Jason, for his & perguntou onde ficar, como era. \\
birthday. Got her to sign a card, & E eu peguei um autógrafo dela \\
sent it outta Afghanistan. Just & pro meu sobrinho, Jason, \\
\hline
\end{tabular}

Cad. Trad., Florianópolis, v. 40, no 3, p. 250-263, set-dez, 2020. 


\begin{tabular}{|l|l|}
\hline three weeks before she died. She & de aniversário pra ele. Pedi \\
asked after Jason by name every & pra ela assinar um cartão, \\
time I saw her after that, and I & mandei para o Afeganistão. Três \\
liked the girl for that, y'know? I & semanas depois ela morreu. Ela \\
been knocking around the security & perguntava de Jason pelo nome \\
game forra long time. There's & sempre que eu a via depois \\
people who'd expect you to take & disso, e eu gostava da garota, \\
a bullet for them and they don't & entendeu? Já ando pelo ramo \\
bother rememb'ring yuh name. & de segurança tem muito tempo. \\
Yeah, she was all right." & Tem gente que espera que você \\
(...) & leve uma bala por eles, e nem se \\
"Musta bin just gone seven that & dão ao trabalho de lembrar seu \\
evening. She was with her friend & nome. É, ela era legal. \\
Ciara Porter. I remember, as they & (...) \\
were going out the door, Mr. & - Deve ter sido logo depois das \\
Bestigui come in. (...) (Galbraith & sete da noite. Ela estava com a \\
87-8) & amiga Ciara Porter. Eu lembro, \\
& quando elas saíram pela porta, \\
& o sr. Bestigui entrou. (...) \\
(Galbraith 95-6)
\end{tabular}

Cad. Trad., Florianópolis, v. 40, no 3, p. 250-263, set-dez, 2020. 


\begin{tabular}{|l|l|}
\hline "Shock?" said Marlene Higson & - Choque? - disse Marlene \\
(...). "You can say that again, & Higson (...). - Nem imagina, \\
when I'd gave 'er up for lost. It & quando dei a menina por \\
near broke my 'eart when she & perdida. Quase partiu meu \\
wen', but I fort I was giving 'er & coração quando ela foi embora, \\
a better life. I wouldna 'ad the & mas eu sabia que era pra ela \\
strenf to do it uvverwise. Fort I & ter uma vida melhor. Eu não \\
was giving 'er all the fings I never & ia ter força pra fazer de outro \\
'ad. I grew up poor, proper poor. & jeito. Não tinha como eu dar a \\
We 'ad nothing. Nothing." & ela todas as coisas que eu nunca \\
(...) & tive. Eu fui criada pobre, muito \\
MARLENE: “And Dez, me & pobre. A gente não tinha nada. \\
boyfriend, see, wasn't too keen- & Nada. \\
you know, with 'er being colored, & (...) \\
it were obvious she weren't 'is. & - E o Dez, meu namorado, \\
They go darker, see; when she & olha só, num gostava muito... \\
were born, she looked white. But & sabe comé, ela era de cor, era \\
I still never would given 'er up if I & óbvio que não era dele. Eles \\
'adn't seen a chance for 'er to get & vão ficando mais escuros, sabe? \\
a better life, and I fort, she won't & Quando ela nasceu, parecia \\
miss me, she's too young. I've & branca. Mas ainda assim eu não \\
gave 'er a good start, and mebbe, & daria ela se não visse a chance \\
when she's older, she'll come and & de ela ter uma vida melhor, \\
find me. And me dream come & e pensei, ela não vai sentir a \\
true," she added, with a ghastly & minha falta, ela é nova demais. \\
show of pathos. "She come'n' & Eu tava dando a ela um começo \\
found me (...)”. (Galbraith 289-90) & bom e de repente, quando \\
& ficasse mais velha, ela ia voltar \\
e me achar. E meu sonho virou \\
realidade - acrescentou ela, com \\
uma demonstração horripilante \\
de pathos. - Ela veio me achar. \\
(...) (Galbraith 289-90) \\
\end{tabular}

Fonte: O Autor

Observando-se as frases originais de Wilson, é possível perceber que a maioria dos desvios da norma padrão presentes em sua fala 
têm por objetivo mostrar não necessariamente um baixo nível de escolaridade (embora pareça ser também esse o caso), mas sim a sua origem jamaicana. Prova disso são expressões como tuh, mi, musta bin, as quais, via de regra, acabam não sendo transportadas na tradução (com a exceção de um pra, um pro e um tem gente). Não se critica aqui tal aspecto da tradução, já que a relação entre o inglês britânico e o jamaicano é bastante específica, e uma transposição disso para o português requereria bastante conhecimento de variedades minorizadas desta língua em relação à variedade brasileira (além de certa criatividade). Todavia, é possível perceber, na tradução das falas de Wilson, uma nítida centralização e até mesmo normalização, já que alguns trechos de sua fala são totalmente compatíveis com a norma padrão.

Por outro lado, analisando-se as falas de Rochelle Onifade e Marlene Higson, fica claro que os vários desvios de concordância e pronúncia em comparação com o inglês padrão visam a demonstrar não apenas um baixo nível de escolaridade, mas também um pertencimento a grupos sociais menos favorecidos (o que se comprova pelo fato de Rochelle ser moradora de rua e Marlene, da periferia de Londres). Em decorrência disso, a tradução das marcas de oralidade na fala de tais personagens não deveria gerar problemas significativos, já que seria possível adaptar a fala delas à de pessoas pertencentes a grupos sociais menos favorecidos no Brasil.

Entretanto, o que se percebe ao se observar a tradução das falas das personagens é uma redução perceptível na quantidade de marcas de oralidade. No caso de Rochelle, apenas qué falá o quê, falá, num, ia ter e deprê saltam aos olhos como expressões realmente orais; nas falas de Marlene, percebem-se os elementos pra, num gostava, sabe comé, tava, ia voltar, de repente com sentido de talvez, além da repetição do pronome ela (inclusive seu uso com a função de objeto). Ainda assim, as marcas orais nas falas traduzidas das duas personagens são bastante pontuais em comparação com o original, de modo que se percebe uma nítida centralização do discurso. 
Por óbvio, não são essas as únicas falas dos personagens selecionados que possuem marcas de oralidade, nem são eles os únicos a realizarem tais expressões na obra em análise. Todavia, os trechos acima foram selecionados em caráter exemplificativo por conterem marcas orais mais nítidas e abundantes.

\section{Conclusão}

A escolha do livro The Cuckoo's Calling para a presente análise não foi aleatória; ao longo da obra é possível perceber a nítida intenção do autor de representar os vários falares das mais diversas regiões do Reino Unido da maneira mais verossímil possível, o que torna tal texto extremamente interessante para pesquisadores do campo da tradução.

Ao se analisar a tradução brasileira, O Chamado do Cuco, em especial no que diz respeito às falas que se desviam da norma padrão, é possível observar uma clara tentativa por parte da tradutora de reproduzir, na medida do possível, as marcas de oralidade contidas no original. Apesar disso, é possível perceber, em alguns momentos, uma certa centralização do registro da obra (e, por vezes, até mesmo uma normalização dos diálogos de menos prestígio). Como consequência disso, falas que, no original, evidenciavam o pertencimento de determinados personagens a certos grupos sociais e econômicos, acabam perdendo suas características essenciais, já que se aproximam bastante da norma culta (à exceção de mínimos desvios). Isso, não exclui, contudo, o esforço louvável da tradutora.

A nosso ver, tais opções de tradução possuem um intuito marcadamente mercadológico, já que marcas de oralidade muito nítidas (em especial aquelas que se aproximam da fala de pessoas de grupos sociais desfavorecidos) não costumam agradar uma parcela significativa do público-alvo das editoras que publicam livros estrangeiros. Ocorre, assim, em geral, uma elevação do registro das falas de certos personagens (em especial das falas daqueles que se 
distanciam mais da norma padrão), a fim de criar a falsa sensação de que ela é realizada por todos os falantes de uma língua. Com isso, infelizmente realiza-se uma manutenção da ideologia do padrão, que acaba por segregar aqueles que não conseguem atingi-lo. Ao fim e ao cabo, a língua (mesmo nas traduções) permanece como um instrumento de controle e segregação social.

\section{Referências}

Amorim, Lauro Maia. "A variação linguística em traduções de 'alta literatura' e de best-sellers de ficção popular”. Tradterm. v. 31, (2018): 136-163, 17/10/2018. SIBiUSP. https://doi.org/10.11606/issn.2317-9511.v31i0p136-163. Disponível em: http://www.revistas.usp.br/tradterm/article/view/150088/148004.

Bagno, Marcos. "A realidade falseada". Gramática pra que te quero?: os conhecimentos linguísticos nos livros didáticos de português, Bagno, Marcos (Org). Curitiba: Aymará, 2010. pp. 114-183.

Galbraith, Robert (a). The Cuckoo's Calling. Nova York: Mulholland Books, 2013.

Galbraith, Robert (b). O Chamado do Cuco. Tradução de Ryta Vinagre. Rio de Janeiro: Rocco, 2013.

Rosa, Alexandra Assis. "Translating orality, recreating otherness". Translation Studies, v. 8, n. 2, (2015): 209-225. Informa UK Limited. http://dx.doi.org/10. 1080/14781700.2015.1017833.

Recebido em: 09/04/2020

Aceito em: 12/07/2020

Publicado em setembro de 2020

Winston Carlos Martins Junior. E- mail: winstoncmartins@gmail.com. ORCID: https://orcid.org/0000-0002-0700-8481. 